\title{
Conformational Plasticity in Human Heme-based Dioxygenases
}

Khoa N. Pham, Ariel Lewis-Ballester, and Syun-Ru Yeh*

Department of Physiology and Biophysics Albert Einstein College of Medicine Bronx, NY 10461, USA.

Table S1. Crystallographic data collection and refinement statistics. Values in parenthesis are for highest resolution shell.

\begin{tabular}{|c|c|c|}
\hline & hIDO1-CO-Trp* & hTDO-CO-Trp \\
\hline PDB Code & 6UBP & 6UD5 \\
\hline X-ray source & NSLS-II (17-ID-2) & APS 31-ID-D \\
\hline Wavelength $(\AA)$ & 0.97931 & 0.97931 \\
\hline Space group & $\mathrm{P} 2{ }_{1} 2_{1} 2_{1}$ & $\mathrm{P} 2{ }_{1} 2{ }_{1}$ \\
\hline \multicolumn{3}{|l|}{ Unit cell dimensions } \\
\hline $\mathrm{a}, \mathrm{b}, \mathrm{c}(\AA)$ & $86.9,97.7,130.6$ & $144.7,154.5,88.3$ \\
\hline$\alpha, \beta, \gamma\left({ }^{\circ}\right)$ & $90,90,90$ & $90,90,90$ \\
\hline Resolution $(\AA)$ & $29.34-2.95$ & $19.97-2.05$ \\
\hline No of unique reflections & $24106(3854)$ & $120121(16664)$ \\
\hline $\mathrm{R}_{\text {merge }}(\%)$ & $9.8(201)$ & $13.2(91.8)$ \\
\hline $\mathrm{R}_{\text {pim }}(\%)$ & $5.6(113)$ & $8.0(55.6)$ \\
\hline $\mathrm{I} / \sigma(\mathrm{I})$ & $12.2(1.2)$ & $7.9(1.9)$ \\
\hline $\mathrm{CC}_{1 / 2}$ & $1.00(0.53)$ & $0.99(0.59)$ \\
\hline Completeness (\%) & $99.9(100.0)$ & $96.7(92.8)$ \\
\hline Redundancy & $7.6(8.0)$ & $6.7(6.7)$ \\
\hline \multicolumn{3}{|l|}{ Refinement } \\
\hline Resolution $(\AA)$ & $29.34-2.95$ & $19.97-2.05$ \\
\hline No of reflections & $22893(1670)$ & $113859(7861)$ \\
\hline $\mathrm{R}_{\text {work }} / \mathrm{R}_{\text {free }}$ & $0.2152 / 0.2641$ & $0.1828 / 0.2174$ \\
\hline \multicolumn{3}{|l|}{ No of atoms } \\
\hline Protein & 5932 & 11632 \\
\hline Ligand/Ions & 120 & 300 \\
\hline Water & 63 & 773 \\
\hline B factor (mean) $\left(\AA^{2}\right)$ & 102.5 & 37.5 \\
\hline \multicolumn{3}{|l|}{ R.m.s. deviations } \\
\hline Bond lengths $(\AA)$ & 0.002 & 0.004 \\
\hline Bond angles $\left({ }^{\circ}\right)$ & 1.228 & 1.232 \\
\hline
\end{tabular}



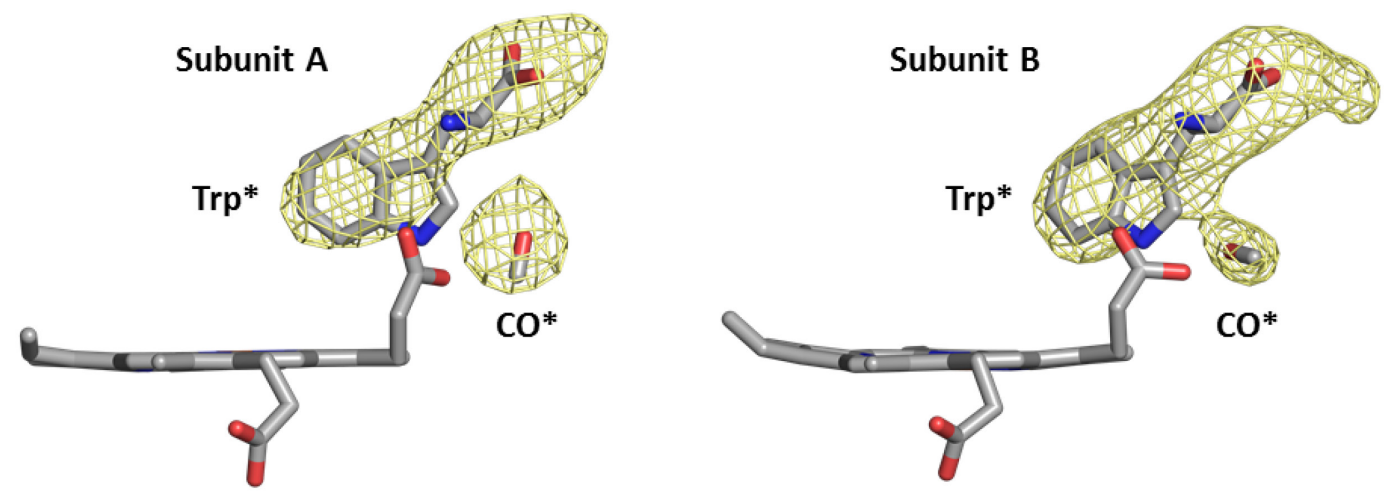

Figure S1. Polder maps associated with Trp and CO bound in the Sa* site of the hIDO1-COTrp* complex. The electron densities associated with Trp* and $\mathrm{CO}^{*}$ are strong; the polder maps are contoured at $4.5 \sigma$. It is noted that the electron density blob next to the Trp* is best modeled with $\mathrm{CO}$. It cannot be assigned to $\mathrm{CN}$, as the parental crystal was thoroughly washed with a large amount of $\mathrm{CN}$-free mother solution prior to $\mathrm{CO}$ purging and reduction; in addition, the absorption spectrum of the crystal confirmed that $\mathrm{CN}$ was fully dissociated from the protein. In addition, the blob is too large to be modeled with a solvent water molecule and too small, and not in the right location, to be accounted by an alternative conformation of the carboxylate or ammonium group of the Trp* or the sidechain of a nearby residue R231. This assignment is supported by flash photolysis studies in free solution, ${ }^{1}$ which demonstrate that, following photolysis, CO and Trp remain bound within the protein matrix.

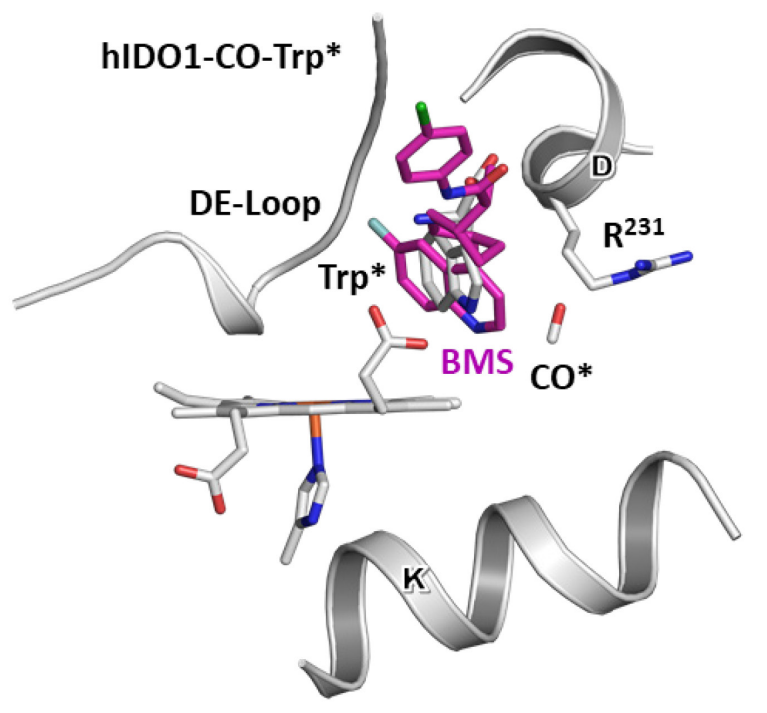

Figure S2. Active site structure of the hIDO-CO-Trp* complex superimposed with BMS986205 taken from the hIDO1-BMS-986205 complex (PDB code: 6DPR). The quinoline group of the BMS-986205 molecule (magenta sticks) overlaps well with the indole ring of the Trp bound in the $\mathrm{Sa}^{*}$ site in the hIDO1-CO-Trp* complex. 


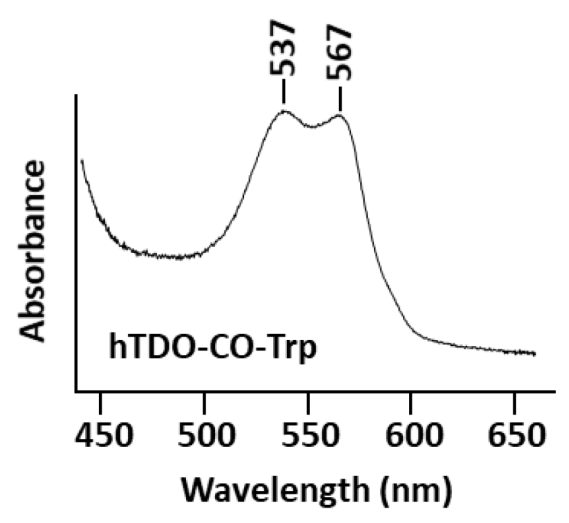

Figure S3. Absorption spectrum of the hTDO-CO-Trp complex crystal. The absorption spectrum is consistent with that obtained in free solution, ${ }^{2}$ confirming the integrity of the crystal.

\section{Reference:}

1. Nickel, E.; Nienhaus, K.; Lu, C.; Yeh, S. R.; Nienhaus, G. U., Ligand and substrate migration in human indoleamine 2,3-dioxygenase. The Journal of biological chemistry 2009, 284 (46), 31548-54.

2. Batabyal, D.; Yeh, S. R., Human tryptophan dioxygenase: a comparison to indoleamine 2,3dioxygenase. Journal of the American Chemical Society 2007, 129 (50), 15690-701. 